\title{
Síndrome de Conn
}

\section{Gregorio Arellano Aguilar, ${ }^{1}$ Ramiro Gálvez Valdovinos, ${ }^{2}$ Gustavo López Ambriz, ${ }^{3}$ Jorge Magaña Reyes, ${ }^{4}$ José Aguirre Trigueros, ${ }^{5}$ Blanca Janeth Pliego Romero, ${ }^{6}$ Erik Santiago Núñez Mojica ${ }^{6}$}

Masculino de 37 años, profesionista; un hermano hipertenso. Refirió hipertensión arterial de cinco años de evolución que ha requerido de manejo por urgencias en al menos cinco ocasiones, con cifras tensionales promedio de 160/100 mmHg y fatiga muscular en las cuatro extremidades; en dichos episodios le detectaron hipocaliemia con cifras entre 2.6 y $3 \mathrm{mEq} / \mathrm{L}$. Con diagnóstico de parálisis periódica hipocaliémica fue abordado con antagonista de angiotensina II, bloqueadores de canales de calcio y potasio IV; posteriormente, un cardiólogo le recetó hasta cuatro fármacos antihipertensivos y potasio oral, sin concluir la causa de la hipertensión.

Acudió a urgencias con cifras de TA de 180/100, cefalea occipitocervical y fatiga muscular importante. A la exploración: TA 180/100; FC 85 lpm; FR 18 rpm; temperatura $36.7^{\circ} \mathrm{C}$; fondo de ojos, cuello, tórax y abdomen normales; fuerza muscular en 3/5 generalizada, no signo de Godet; pulsos y llenado capilar normales; electrocardiograma con aplanamiento de onda $\mathrm{T}$ y onda $U$ prominente. Los paraclínicos mostraron aldosterona plasmática 455,2 pg/mL; renina plasmática $0.17 \mathrm{ng} / \mathrm{mL} / \mathrm{H}$, con índice $\mathrm{A} / \mathrm{R}=26.7$; potasio $3.2 \mathrm{mEq} / \mathrm{L}$; perfil tiroideo normal, al igual que ácido vanilmandélico en orina. Se llegó al diagnóstico de hiperaldosteronismo primario. Por cifras tan altas de hipertensión, no se realizó prueba de inhibición de aldosterona con carga

\footnotetext{
${ }^{1}$ Médico Internista. División de Medicina.

${ }^{2}$ Cirujano General. División de Cirugía.

3 Anestesiólogo. División de Cirugía.

${ }^{4}$ Radiólogo. Departamento de Imagenología.

5 Patólogo. Departamento de Anatomopatología.

${ }^{6}$ Interno de pregrado.
}

Hospital Ángeles León.

Correspondencia:

Dr. Gregorio Arellano Aguilar

Correo electrónico: gregareag@gmail.com

Aceptado: 27-09-2016.

Este artículo puede ser consultado en versión completa en http:// www.medigraphic.com/actamedica de cloruro de sodio; se solicitó tomografía computada, que mostró adenoma de la glándula suprarrenal izquierda, lo que confirmó el síndrome de Conn (Figuras 1 y 2). Se le manejó con esplerenona y bloqueadores de los canales de calcio, preparándolo para adrenalectomía izquierda por laparoscopia (Figura 3). Histopatológicamente, se confirmó adenoma cortical adrenal (Figura 4).

El síndrome de Conn, ${ }^{1}$ descrito en 1955, está caracterizado por un adenoma productor de aldosterona (APA). Es uno de los siete subtipos que actualmente conforman al hiperaldosteronismo primario (HAP), siendo el APA y la hiperplasia bilateral idiopática de la capa glomerulosa de la corteza de la glándula suprarrenal los dos subtipos más frecuentes de HAP y correspondiendo a las dos etiologías más comunes de hipertensión arterial secundaria. La prevalencia de HAP se estima entre cinco y $13 \%$ de todos los pacientes con hipertensión arterial. ${ }^{2}$

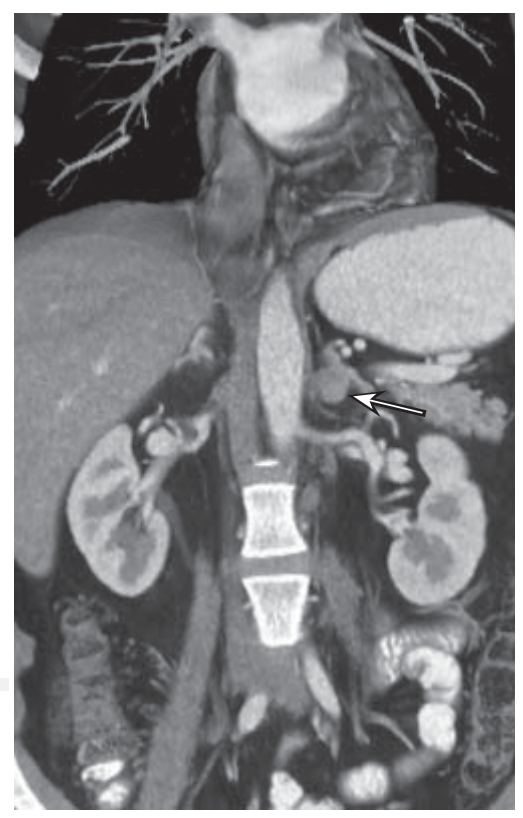

Figura 1. Reconstrucción coronal de tomografía computada en fase arterial, a nivel toracoabdominal; se muestran ambas glándulas suprarrenales, en la izquierda se identifica un nódulo circular con reforzamiento (flecha). 

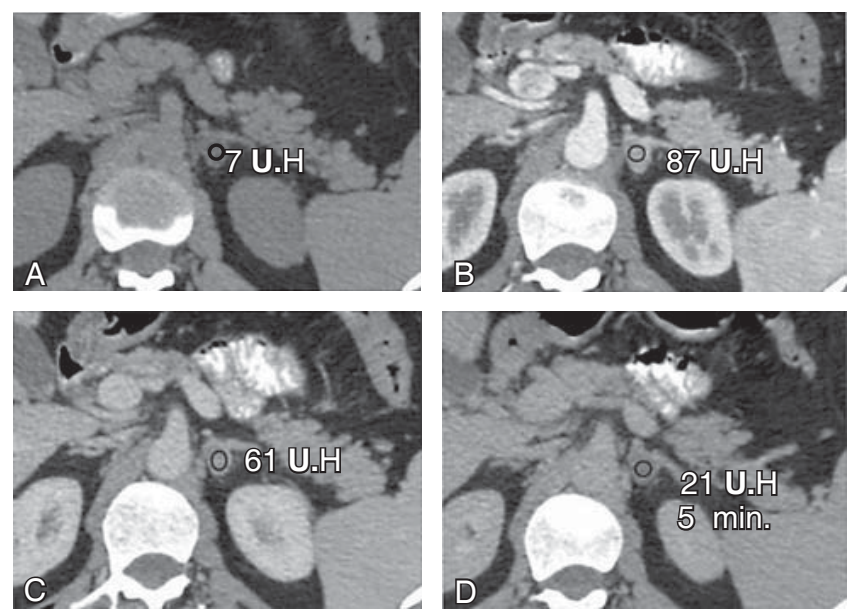

Figura 2. Tomografía axial computada a nivel de ambas glándulas suprarrenales en diferentes fases, A simple; B arterial, C venosa y $D$ tardía a los cinco minutos. En $A$, el nódulo demuestra > $10 \mathrm{UH}$, sugiere adenoma; intenso realce en $B$ con lavado acelerado en D a los cinco minutos.
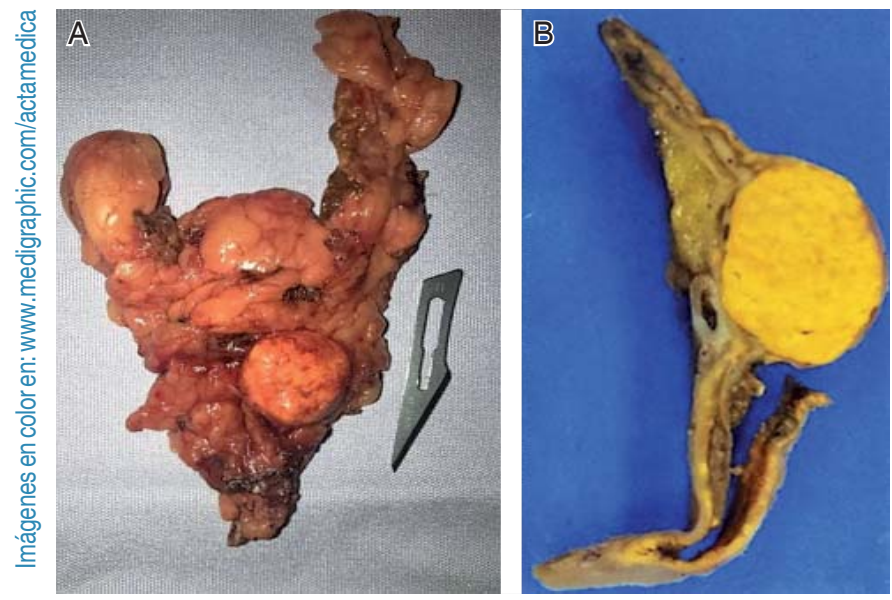

Figura 3. En A, pieza quirúrgica con adenoma de la glándula suprarrenal izquierda; en B, adenoma cortical adrenal, tumor nodular con bordes bien definidos de apariencia capsular, amarillo brillante.

El diagnóstico de HAP se confirma utilizando la relación aldosterona/renina plasmáticas, seguida de una prueba de supresión de aldosterona; éstas deben realizarse en a) pacientes con hipertensión e hipocaliemia; b) pacientes con hipertensión resistente a tratamiento (uso de tres fármacos antihipertensivos); c) hipertensión severa
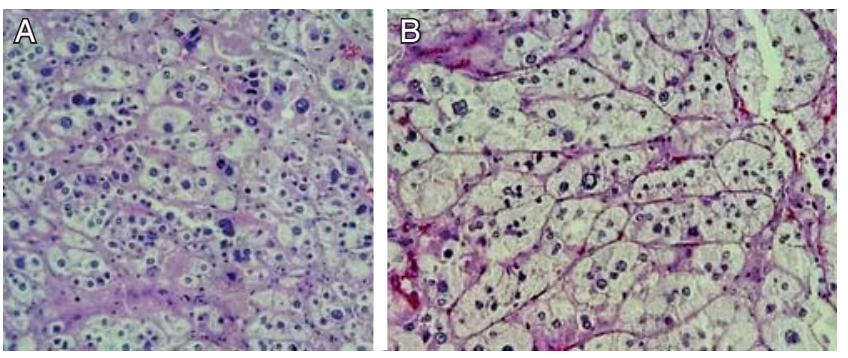

Figura 4. Adenoma de glándula suprarrenal izquierda con patrón trabecular, células redondeadas, citoplasmas eosinófilo-abundantes, pleomorfismo nuclear marcado y pseudoinclusiones nucleares. Tinción hematoxilina-eosina; en $A, 10 x$, en $B, 40 x$.

( $\geq 160 \mathrm{mmHg}$ sistólica o $\geq 100 \mathrm{mmHg}$ ) diastólica; d) hipertensión e incidentaloma; e) hipertensión arterial en paciente joven. Todas ellas estaban presentes en nuestro paciente, excepto el incidentaloma, pues la búsqueda del adenoma fue intencionada.

La medición de aldosterona ${ }^{3}$ y de renina plasmática debe efectuarse entre las ocho y 10 horas AM en el paciente ambulatorio; la relación de aldosterona/renina incrementada debe confirmarse con una prueba de supresión de aldosterona. El estudio de imagen de elección es la tomografía computada de glándulas suprarrenales; la adrenalectomía ${ }^{4}$ en individuos con APA normaliza la hipocaliemia en todos ellos; la hipertensión arterial ${ }^{5}$ mejora en todos los casos y el 30 a $60 \%$ de los enfermos se curan; en aquéllos con cuadros de afección bilateral de las glándulas suprarrenales, la adrenalectomía uni- o bilateral corrige la hipertensión; desde el punto de vista médico, deben ser tratados con antagonistas de receptores de mineralocorticoides.

\section{REFERENCIAS}

1. Conn JW, Louis LH. Primary aldosteronism: a new clinical entity. Trans Assoc Am Physicians. 1955; 68: 215-231.

2. Aronova A, lii TJ, Zarnegar R. Management of hypertension in primary aldosteronism. World J Cardiol. 2014; 6: 227-233.

3. Uresti FE, Saucedo TL, Gámez BH, Melo GM, Valdés CE, García LL. Síndrome de Conn. Med Int Méx. 2015; 31: 210-216.

4. Maestre MM, Candel AM, Terol GE, Gonález VF, Albarracin MA. Suprarrenalectomía laparoscópica: la mejor opción de tratamiento quirúrgico. Cir Cir. 2013; 81: 196-201.

5. Gómez RP, Hernández JD, Vergara LA. Hiperaldosteronismo primario, el escrutinio y su importancia en pacientes hipertensos. Rev Mex Endocrinol Metab Nutr. 2015; 2: 22-28. 